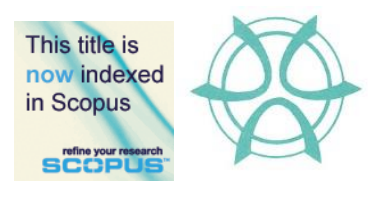

PLANNING MALAYSIA:

Journal of the Malaysian Institute of Planners

VOLUME 16 ISSUE 3 (2018) Page 208 - 220

\title{
EXPLORING POSSIBLE USAGE FOR ELEVATED HIGHWAY INTERSTITIAL SPACES: A CASE STUDY OF DUKE AND AKLEH, KUALA LUMPUR
}

\author{
Mohamed Ikhwan Nasir Mohamed Anuar ${ }^{1} \&$ Raziah Ahmad ${ }^{2}$ \\ Faculty of Architecture, Planning and Surveying \\ UNIVERSITI TEKNOLOGI MARA, MALAYSIA
}

\begin{abstract}
Kuala Lumpur has seen rapid development of mass amount of highway infrastructure. Although elevated urban highways in Greater Kuala Lumpur may have relieved the intercity and interstate traffic, the presence of this urban infrastructural landscape promotes the creation of lost spaces. The construction of the highways, primarily the elevated ones, often create spaces underneath the structure that are often neglected in mainstream planning and design. This paper aims at investigating typologies of interstitial spaces and its characteristics beneath elevated highway based on available literature as well as to explore the possibilities of usage for spaces below the elevated highway. This research employs qualitative method that involves primary and secondary data collection. The primary data were gathered through site observational study at two major elevated highways in the Greater Kuala Lumpur area -DUKE 1 Highway and AKLEH Highway. A review and content analysis of documents related to urbanization and planning transportation provide secondary data. Findings from this study suggest that [1] although the highways enhance connectivity and ease traffic movement, it also leads to abundance of wasted land and spaces [2] an improved understanding of the typologies and characteristics of these interstitial spaces shall aid in the improvement of their future usage.
\end{abstract}

Keywords: infrastructural landscape, interstitial spaces, elevated highway 
PLANNING MALAYSIA

Journal of the Malaysia Institute of Planners (2018)

\section{INTRODUCTION}

Studies and research in landscape urbanism field have focused on infrastructure as the most important generative public landscape. Mossop (2006) describes that these omnipresent urban environments have been considered and evaluated solely on technical criteria and somehow exempted from having to function socially, aesthetically, or ecologically. In a study by SWA Group (2011), it was highlighted in the context of our rapidly changing urban environment, infrastructure is experiencing a paradigm shift where multiple-use programming and the integration of latent ecologies is a primary consideration. Redefining modern infrastructure requires a multi-disciplinary team of landscape architects, designers, engineers, architects and planners to fully realize the benefits to our cultural, social and natural systems. Such a re-examination of infrastructural space involves the recognition that all types of space are valuable, not just the privileged spaces of more traditional parks and squares, and they must therefore be inhabitable in a meaningful way. Hence, the mono functional realm of infrastructure requires new approaches and more sustainable design concepts for difficult spaces particularly under elevated highways and as well as complex transit interchanges must therefore be explored and examined. These spaces make up a large proportion of urban land and are of interest to many stakeholder groups. While they are often viewed as dangerous or unsightly, they can be an economic, social, and ecological resource (Kremer \& Hamstead, 2015; Anderson \& Minor, 2016).

Like most cities in the developing world, Kuala Lumpur has experienced rapid development which has left the city, in many respects, disjointed and lacking in spatial coherence in both visual and physical aspect. Described briefly in the Kuala Lumpur Structure Plan 2020, major roads primarily highways and rail infrastructure, have in many places effectively divided adjacent spaces and areas or neighbourhoods that remain physically close but virtually inaccessible to each other. Elevated highways are described as pieces of infrastructure, which seldom attract people's affection and pose a constant provocation, although practical and financial reasons suggest to simply accepting their presence. (Harnack \& Cohler, 2011). Following this, Crisman, (2012) stated that the resulting interstice, "a space that intervenes between one thing and another," often generates seemingly uninhabitable zones and problematic discontinuities in the physical and social fabric. Issues relating to the formation and unclear function of these lost spaces has mostly been discussed in the western world and still limited within surrounding region (Qamaruz-Zaman et al., 2013; Clements, 2013; Sanches \& Pellegrino, 2016).

Scholars, designers and planners, spanning multiple fields of practice, have noted that the issue is a result from of a lack of integration during the planning and design process, and that the problem of left over spaces is indeed a gap that is to be addressed (Trancik, 1986; Mossop, 2006; Crisman, 2009; 
Mohamed Ikhwan Nasir Mohamed Anuar \& Raziah Ahmad

Exploring Possible Usage for Elevated Highway Interstitial Spaces: A case study of DUKE and AKLEH, Kuala Lumpur

Prasetyo \& Iverson 2014; Akinci, Demir, \& Demirel, 2016). Barter's study (2004) disclosed significant issues about highways in Kuala Lumpur which demonstrates the high ratio of highways as compared to the number of population (68 meters per 1000 population). Therefore, to address the issues at hand, there is a need to understand the current situation of the existing left-over spaces under the elevated highways in Kuala Lumpur. This paper aims at investigating typologies of interstitial spaces and its characteristics beneath elevated highway based on available literature as well as to explore the potential of usage for spaces below the elevated highway.

\section{LITERATURE REVIEW}

\section{Elevated Highways and the Emergence of "Lost Spaces"}

Regarded as the most commonly used and economical mode of human transportation, highway transportation is the most important connection in the landscape between rural and urban areas. The creation of 'Elevated highway' or 'flyover' as commonly referred to in the United Kingdom and most Commonwealth countries (Akinci et al., 2016) has been mentioned as one of the major drivers of landscape change worldwide. Adding to this, landscape fragmentation caused by transportation infrastructure has a number of effects on almost all components of landscapes, including aesthetic, ecological, historical, and recreational qualities (Forman et al., 2011).

Elevated highways have often been built in the following urban areas: surround urban periphery, river bank, industrial area and the one that cut through the low-income housing (Biesecker, 2015). The development of this kind infrastructure would primarily increase the accessibility and mobility of urban dwellers but at the same time become barriers that separate district or neighbourhood. Saouma (2008) conducted a thorough analysis of the impact of elevated highways in Bourj Hammoud, Beirut. Her findings revealed six types of impacts as shown in Figure 1. During the early phase of the construction of elevated highways, this infrastructure has not only promoted growth and development of cities, it also became a symbol of progression, increased accessibility, and mobility to urban residents (a). Because of its efficiency that have shortened the travelling distances, elevated highways have dominated the urban fabric (b). Such intrusion of urban structure has given bad impact in which it creates physical and psychological barrier that segregates neighbourhoods (c). Additionally, the undefined spaces under the elevated highway have often been misused (d) as it only allows minimum natural lighting and poor ventilation (e). Due to its poor quality and accessibility, the underpass spaces became lost spaces without functional activities (f). 
(a)
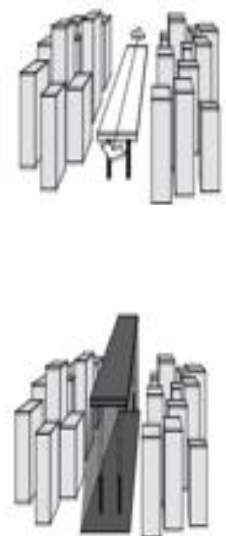

(d)

(e)

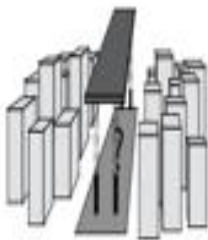

(b)

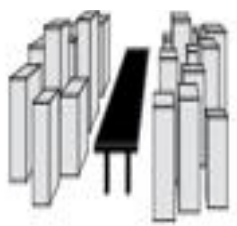

(c)
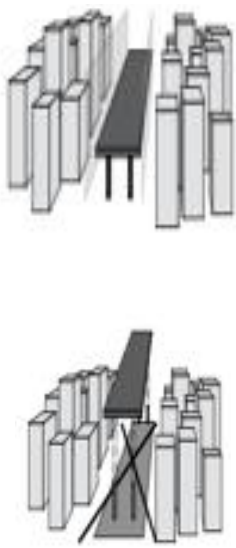

(f)

Figure 1: The six impacts of elevated highways in Beirut Source: Saouma (2008)

As a result from increasingly fast high performance infrastructural development particularly highways that dissects through urban spaces, empty and leftover spaces would present within the urban fabric. The emerging of undefined spaces along and under elevated highways affect the way we experience the city. They disconnect neighbourhoods, produce undesirable views, and act as physical and psychological barriers making the pedestrian experience unpleasant (Trancik, 1986). The unclear and inappropriate use of the vacant spaces under elevated highways can lead to social and economic problems. In addition, these unwanted spaces may lowering the value of adjacent properties (Halprin, 1966).

Elevated highways are described as pieces of infrastructure, which seldom attract people's affection and pose a constant provocation, although practical and financial reasons suggest to simply accepting their presence (Harnack \& Cohler, 2011). Adding to this, Crisman (2012) stated that the resulting interstice, "a space that intervenes between one thing and another," often generates seemingly uninhabitable zones and problematic discontinuities in the physical and social fabric. The author furthermore explained that these edges and leftover spaces are rarely considered worthy of design attention for they are ugly, ordinary and out of the way, they present difficult existing conditions and unglamorous realities.

The by-product of massive infrastructural development particularly elevated highways often results in residual spaces considered as mere voids and lost opportunities (Anuar \& Ahmad, 2017), which have always emerged as the number of highways increased due to the needs and demands. The areas under highway viaducts and bridges are defined as dead spaces. Wall (2011) described several key characteristics can be examined in relation to the features of 
Mohamed Ikhwan Nasir Mohamed Anuar \& Raziah Ahmad

Exploring Possible Usage for Elevated Highway Interstitial Spaces: A case study of DUKE and AKLEH, Kuala Lumpur

interstitial spaces generally located between or under elevated highways: they are small, irregular and enclosed. These spaces are often made as small as possible, in order to balance with the need to minimize the area of land for the high capacity infrastructure while maximizing the efficiency of the system. The spaces are also enclosed on at least one side, and in this case it is clearly apparent that the space is dominated on one side by the expressway.

In addition to the general characteristics of interstitial space as discussed by Wall (2011), the authors furthermore highlighted that left over spaces also generally appears to be undefined in use, ownership, management and function. These leftover spaces often project a sense of abandonment in contrast to the highly managed and planned infrastructure above it (Anuar, Saruwono, \& Said, 2014). Landscape architecture sees them as part of urban space's landscape system, land use, traffic and public areas (Akinci et al. 2016). These interstitial spaces they are often overlooked, and are often relegated as 'wastelands', 'derelict areas' and 'urban voids' as described by Doron (2000). They represent socio-economic abandonment and dereliction and are excluded from the ideal, as they run contrary to the dominant desired image of the city. Interstitial, dilapidated, dis-used and marginal sites punctuate the often highlighted and controlled formal public spaces, parks and the everyday spaces of the modern city. They are referred to in various literatures and discussions from the realms of architecture, planning, design and urban theory as 'lost space' (Trancik, 1966), 'dead zones' (Doron, 2000) and 'the shadow' (Malterrre-Barthes, 2011).

\section{RESEARCH METHODOLOGY}

\section{Scope of Study}

This study focuses on the impact of elevated highways with regards to the creation of lost spaces and how an improved understanding of the characteristics of these spaces can help designers and planners to better utilize it. It is based on the perception and observation of the authors during a period of site visits.

\section{Case Study}

This research employs a case study which allows the authors to examine contemporary phenomenon within the real-life situation using the qualitative method. Site observation and data collection of the left over spaces on site were guided by a systematic framework established by Franck (2011). The framework allowed the authors to document systematically the six variables vis-à-vis activities, location, time, characteristics, site adaptation as well as the status of the activity within the studied site. The observed variables were analysed and summarized as represented in Table 2. Duta Ulu Kelang Expressway or abbreviated as DUKE expressway was selected as the first case study. It is elevated, primarily parts that run across dense urban communities and 
neighbourhoods resulting in the presence of multiple interstitial spaces. Diverse in form, these spaces share the common conditions of enclosure, emptiness and in some parts unclear function. Along the expressway, these by products are enclosed by large scaled infrastructural forms in contrasting scale to the void it holds below. The site of the case study is located underneath the DUKE highway near the Jalan Pahang ramp and Sentul Pasar Interchange (Figure 2). Presently, the surrounding major site context includes religious institutions - Jamiul Ehsan Mosque, commercial lots as well as a newly built mix residential tower - The Reach @ Titiwangsa.

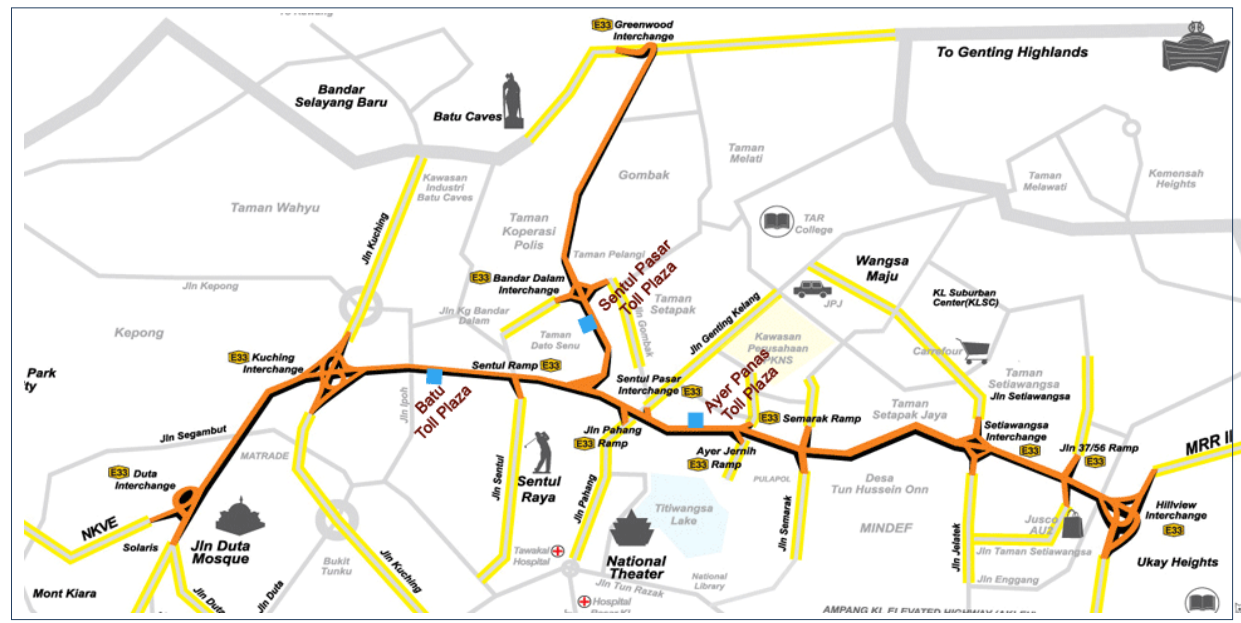

Figure 2: DUKE Highway showing route of Jalan Pahang Ramp and Sentul Pahang Interchange
Source: klia2.info

The second case study is the areas underneath the Ampang Kuala Lumpur Elevated Highway (AKLEH), ranging from Kampung Kuala Ampang MRR2 interchange to the Dato' Keramat interchange. The two case studies were selected as both of them possesses some of the largest amount of lost spaces underneath elevated highways in Kuala Lumpur and were deemed appropriate to be selected as case studies.

\section{Case Study 1: DUKE Highway Phase 1: Jalan Pahang Ramp - Sentul Pasar Interchange}

The activity recorded showcases various formal as well as informal activities within site. Sidewalks and roadside curbs were seen being used as informal spaces for commercial activities. Many of the social and spatial characteristics by the selling of food and beverages showcased a publicly owned, flat surface with a constant flow of passer by pedestrians (Figure 3). The activities usually occur in 
Mohamed Ikhwan Nasir Mohamed Anuar \& Raziah Ahmad

Exploring Possible Usage for Elevated Highway Interstitial Spaces: A case study of DUKE and AKLEH, Kuala Lumpur

the morning until late in the evening as the site gets relatively dark and the number of pedestrians in the area dwindles.

The commercial activity within site was deemed as informal and temporary as it lacks proper amenities such as kiosk, proper sitting area or tables. It is regarded as illegal hence the "dilarang berjaja" signage. Apart from the space being used for selling of food products, the nature of the space which is covered by the overhead deck of the highway allowed the space to be utilized as a temporary shelter by pedestrians and motorcyclist from the rain (Figure 3 ).
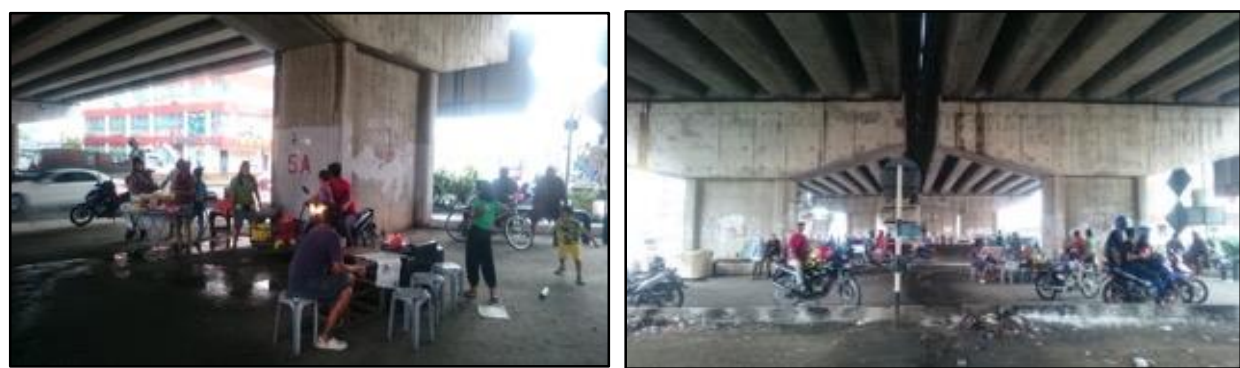

Figure 3: Selling of food and motorcyclists taking refuge underneath DUKE near the Jalan Pahang - Sentul Pasar Interchange Source: Author

Other activities and use of space included informal but allowable parking sites; since no marking of proper parking lots was observed during the time of the fieldwork and vehicles were observed and recorded being parked in unmarked open spaces as shown in Figure 4. Vehicles were seen being parked here primarily during the daytime, and as night falls, the space would be left empty, unused and unattended. The unclear function of the space also attracted illegal activities, as some parts of the spaces was recorded being utilized as illegal dumping sites (Figure 4).
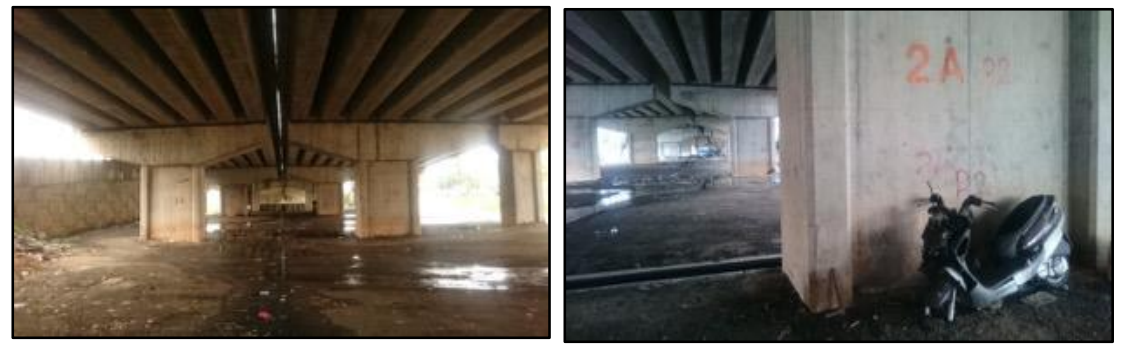

Figure 4: Ambiguity and vagueness of specific function is represented in these two photographs underneath DUKE. Source: Author 
PLANNING MALAYSIA

Journal of the Malaysia Institute of Planners (2018)

\section{Case Study 2: Ampang Kuala Lumpur Elevated Highway (AKLEH). Kampung Kuala Ampang -}

Several key characteristics can be examined in relation to the features of interstitial spaces generally located between or under elevated highways: they are small, irregular and enclosed (Wall, 2011). These characteristics can be associated with the spaces present under several areas of the AKLEH. In the case of AKLEH, the notion of Wall's characteristics was present, the spaces were indeed small, irregular and enclosed. These spaces are made as small as possible, in order to balance with the need to minimize the area of land for the high capacity infrastructure while maximizing the efficiency of the system.

Through observation, it was also apparent that the available spaces under the structure are also irregular in form as they are definite to the forms of the above structure. The elevated structure also echoes the flow of the Ampang River in which the structure is built on top of (Figure 5). The spaces are also enclosed on at least one side, and in this case, it is clearly apparent that the space is dominated on its overhead plane by the expressway and in most areas flanked by retaining walls along the river bank. The sense of scale between the infrastructural network and the human activity is a contrasting site to view. Human scaled activities present at this site remains insignificant if it was to compare with the function of the massive structure positioned overhead. The discontinuation between the interstitial spaces is furthermore accentuated by the contrast in scale between the structure and the adjacent neighbourhood. Moreover, the massive form and high paced nature of the AKLEH intensifies the juxtaposition of scale. Wall (2011) furthermore highlighted that left-over spaces also generally appear to be undefined in use, ownership, management and function. As observed, the spaces underneath AKLEH suggest the same (Figure 5). Vacant spaces still suggest vagueness in terms of specified use as well as function.

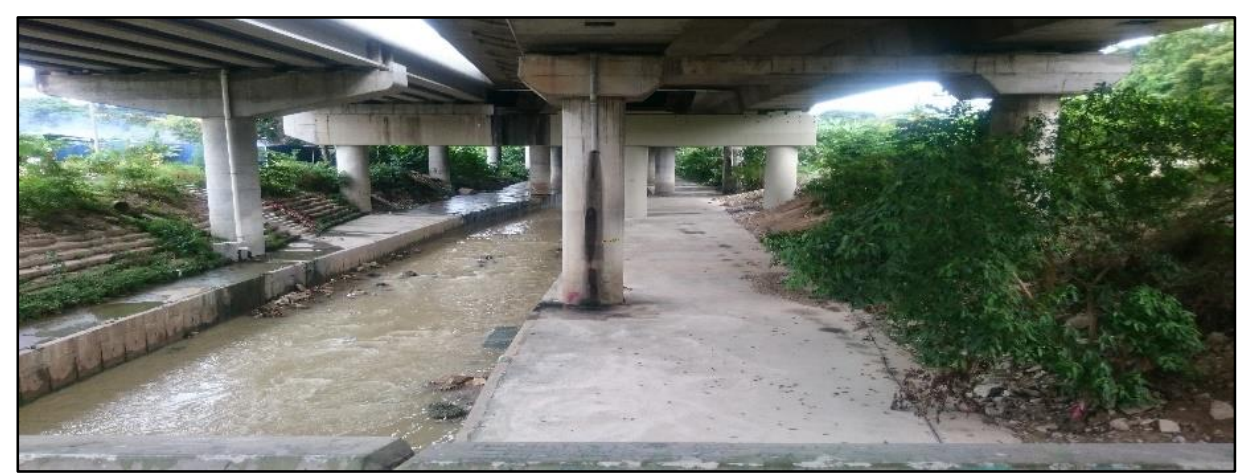

Figure 5: The neglected vacant space below AKLEH negligence devoid of specific function Source: Author 
Mohamed Ikhwan Nasir Mohamed Anuar \& Raziah Ahmad

Exploring Possible Usage for Elevated Highway Interstitial Spaces: A case study of DUKE and AKLEH, Kuala Lumpur

These leftover spaces project a sense of abandonment and lost opportunities in contrast to the highly managed and planned infrastructure above it. The spaces underneath AKLEH were in contrast to the spaces observed underneath DUKE, where activities observed were limited to [1] people using the concrete bank of the river as passage ways and [2] people sat and fished for aquatic life on some parts of the riverbank (Figure 6).
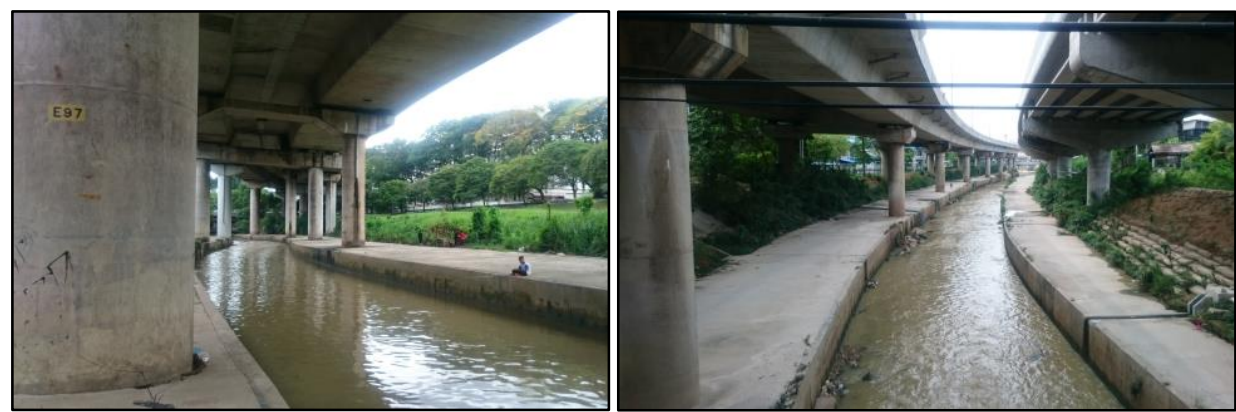

Figure 6: Spaces underneath AKLEH are visually more attractive as compared to the one at DUKE, but they are rather less functional and utilizable Source: Author

\section{RESULTS AND FINDINGS}

The case of DUKE and AKLEH puts forth multiple key issues and challenges, the fragmentary nature of these lines of infrastructure has sealed off the urban fabric that has minimal connection to the adjacent spaces. The summary of the six variables that were observed and analysed at DUKE and AKLEH is shown in Table 2.

Table 2: Summary of site observation of DUKE [D] and AKLEH [A]

\begin{tabular}{|l|l|l|l|l|l|}
\hline \multicolumn{1}{|c|}{ Activity } & \multicolumn{1}{|c|}{ Location } & \multicolumn{1}{c|}{ Time } & Site Characteristics & \multicolumn{1}{|c|}{ Adaptation } & \multicolumn{1}{c|}{ Status } \\
\hline $\begin{array}{l}{[\text { D]Selling of }} \\
\text { food items }\end{array}$ & $\begin{array}{l}\text { Near } \\
\text { roadside, on } \\
\text { road shoulder }\end{array}$ & $\begin{array}{l}\text { Daytime } \\
\text { only, from } \\
\text { mid- } \\
\text { morning to } \\
\text { late } \\
\text { evening }\end{array}$ & $\begin{array}{l}\text { Adjacent to passing } \\
\text { road (Jalan Pahang) } \\
\text { and pedestrian ways }\end{array}$ & $\begin{array}{l}\text { Temporary, } \\
\text { modular and } \\
\text { non-permanent } \\
\text { tables and stools }\end{array}$ & $\begin{array}{l}\text { Illegal but } \\
\text { sometimes } \\
\text { tolerated. } \\
\text { Unclear }\end{array}$ \\
\hline $\begin{array}{l}{[\text { D]Vehicular }} \\
\text { parking }\end{array}$ & $\begin{array}{l}\text { Inner part of } \\
\text { the space } \\
\text { underneath } \\
\text { DUKE }\end{array}$ & $\begin{array}{l}\text { Daytime } \\
\text { only. } \\
\text { Morning } \\
\text { until late } \\
\text { evening. }\end{array}$ & $\begin{array}{l}\text { Expansive, } \\
\text { unobstructed } \\
\text { surface, somewhat } \\
\text { secluded, dark. }\end{array}$ & $\begin{array}{l}\text { Some areas have } \\
\text { wire fencing, } \\
\text { but no parking } \\
\text { lot markings }\end{array}$ & $\begin{array}{l}\text { Tolerated, } \\
\text { legal. } \\
\text { Unclear as } \\
\text { space is not } \\
\text { formal } \\
\text { parking area }\end{array}$ \\
\hline $\begin{array}{l}{[\text { D]Temporary }} \\
\text { shelter from } \\
\text { weather }\end{array}$ & $\begin{array}{l}\text { Near } \\
\text { roadside } \\
\text { (Jalan } \\
\text { Pahang) }\end{array}$ & $\begin{array}{l}\text { During } \\
\text { rainy } \\
\text { weather. }\end{array}$ & $\begin{array}{l}\text { Open space, } \\
\text { permanent sitting } \\
\text { near elevated } \\
\text { highway's columns. }\end{array}$ & $\begin{array}{l}\text { Permanent } \\
\text { sitting made } \\
\text { from galvanized } \\
\text { steel pipe set up }\end{array}$ & $\begin{array}{l}\text { Tolerated, } \\
\text { legal }\end{array}$ \\
\hline
\end{tabular}


PLANNING MALAYSIA

Journal of the Malaysia Institute of Planners (2018)

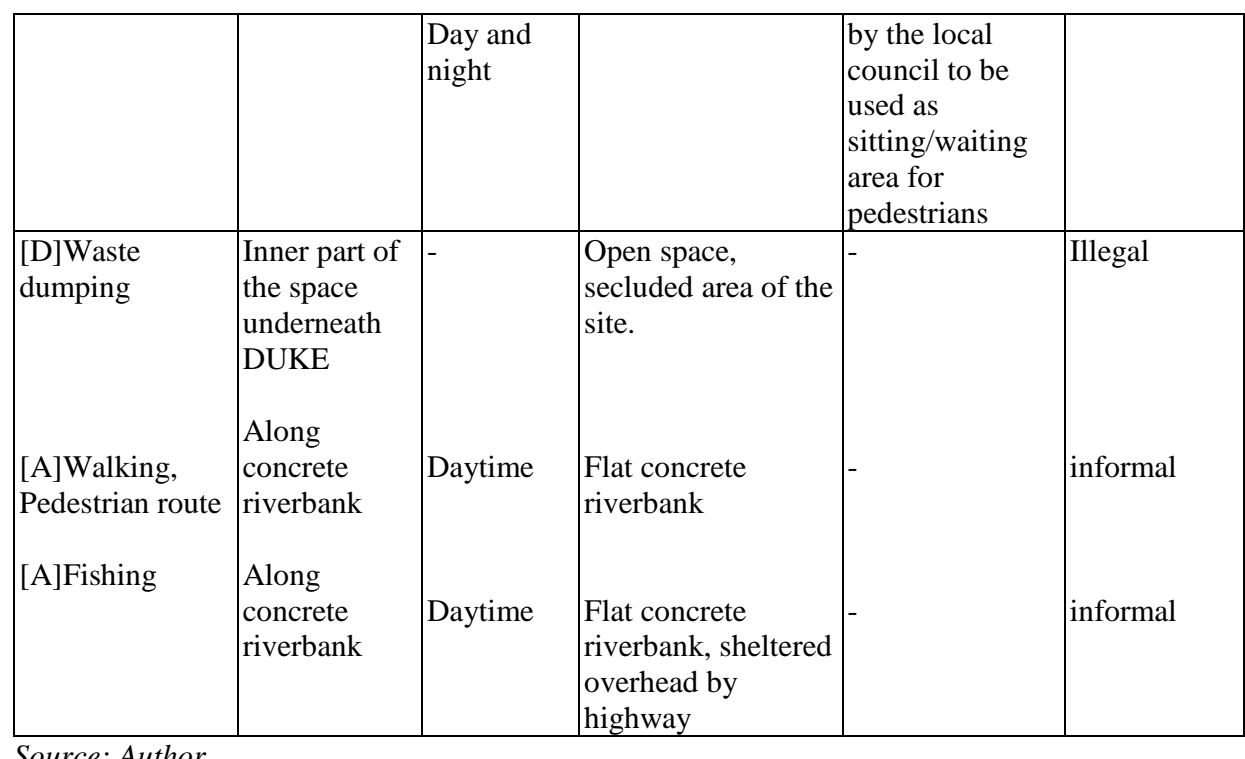

Based on Table 1, the characteristics of the spaces under DUKE and AKLEH resemble Sola-Morales' (1995) descriptions in which these are the spaces with unincorporated margins, interior islands, void of activity, oversights that often un-inhabited, unsafe and un-productive. In a nutshell, they are foreign to the urban system, mentally exterior in the physical interior of the city, its negative image, as much a possible alternative. Apart from that, findings from both case studies spot three similarities with the Saouma's (2008) six impacts of the elevated highways in Beirut. First, the underneath space at DUKE has allow minimal day light, making this space pretty gloomy, dull and less attractive. Second, the presence of AKLEH creates both physical and psychological barriers which segregate and minimize accessibility within the adjacent neighbourhood. Finally, the characteristics of undefined spaces underneath DUKE and AKLEH are rather similar to the underpass spaces in Bourj Hammoud, Beirut. It is fuzzy, misused and unwanted by the communities which could to a certain degree be associated with potentials of unhealthy and illegal social activities (Halprin 1966; Branas et al., 2011).

As described in the Kuala Lumpur Structure Plan 2020, infrastructure has caused adjacent spaces and areas or neighbourhoods to be divided and that they remain physically close but virtually inaccessible to each other. This key issue is significantly apparent through the observation of these case studies. The lack of continuity at the ground level in terms of support activities, scale as well as a definitive space function has caused severe fragmentation of adjacent spaces primarily effecting the surrounding areas. This physical and visual fragmentation is furthermore intensified with the issue of ownership as well as permissible use. 
Mohamed Ikhwan Nasir Mohamed Anuar \& Raziah Ahmad

Exploring Possible Usage for Elevated Highway Interstitial Spaces: A case study of DUKE and AKLEH, Kuala Lumpur

Further observations and analysis of the site could be suggested as a measure for a better understanding of how people actually utilize these seldom seen spaces. Most of the activities observed were temporary and informal in nature. The challenge is now for both designers and planners to understand how people adapt to these lost spaces and develop a plan that is systematic and practical for these spaces but still, in the words of Franck (2011), allow citizens opportunities to imagine and create their own scenarios.

\section{CONCLUDING REMARKS}

Findings from this study suggest that location and characteristics are the most significant variables which determine types of activities and level of users' adaptation towards the ambience of undefined spaces created by the elevated highways. Underneath spaces at DUKE illustrate the more accessible the spaces within the adjacent neighbourhood, the more likely temporary activities take place, particularly during day time. In sum, the presence of undefined and less functional spaces under the elevated DUKE and AKLEH are certainly foreign to the overall urban system. The occurrence of leftover spaces in urban fabric should be minimized. Urban intervention which could transform negative spaces into a more usable and multifunctional public spaces, primarily under the elevated highway shall be embraced by urban designers and other stakeholders. In the New Urbanism Paradigm, the tactical approach inspired from urban experiment has become paramount. It intended to temporarily or permanently transform underused spaces into outdoor eating areas, park-like spaces or gathering place through beautification. The phrase use in the Project for Public Spaces "lighter, quicker, cheaper" shall be adopted to promote various intervention for positive change in neighbourhood and communities. The suggested approach through tactical urbanism seems feasible as an effective remedy for redesigning the unused spaces which could be transform into a meaningful place with a sense of ownership and attachment.

\section{ACKNOWLEDGEMENT}

The authors would like to thank Universiti Teknologi MARA (UiTM) for funding this research through the LESTARI Grant (Project Code: 600-RMI/DANA 5/3/LESTARI (85/2015), which is provided by The Institute of Research Management and Innovation (IRMI), Universiti Teknologi MARA, Shah Alam Selangor.

\section{REFERENCES}

Akinci, Y. C., Demir, S., \& Demirel, O. (2016). Landscape architecture and creating innovative spaces under highway overpasses. In R. Efe, İ. Cürebal, A. Gad, \& B. Tóth (Eds.), Environmental sustainability and landscape (pp. 1-10). (n.p.): St. Kliment Ohridski University Press. 
Anderson, E. C., \& Minor, E. S. (2017). Vacant lots: An underexplored resource for ecological and social benefits in cities. Urban Forestry \& Urban Greening, 21, 146-152.

Anuar, M. I. N. M., \& Ahmad, R. (2017). Elevated highways and its lost spaces: A review of Kuala Lumpuree s seldom seen. Environment-Behaviour Proceedings Journal, 2(6), 279-291.

Anuar, M. I. N. M., Saruwono, M., \& Said, A.S. (2014, November). Within the shadows: Infrastructural landscape as urban space reconnector. Regional Conference on Science, Technology and Social Sciences (RCSTSS 2014). November 23-25, 2014, Cameron Highlands, Pahang, Malaysia.

Barter, P. (2004). Transport, urban structure and lock-in' in the Kuala Lumpur Metropolitan Area. International Development Planning Review, 26(1), 1-24.

Biesecker, C. (2015). Designing urban under highway spaces (Doctoral dissertation). University of Georgia, Athens, Georgia, USA.

Branas, C., Cheney, R., Macdonald, J., Tam, V., Jackson, T., \& Ten Have, T. (2011). A difference-in-differences analysis of health, safety, and greening vacant urban space. American Journal of Epidemiology, 174(11), 1296-1306.

Clements, G. R. (2013). The environmental and social impacts of roads in Southeast Asia (Doctoral dissertation). James Cook University, Townsville, Australia.

Crisman, P. (2009). Inhabiting the in-between: Architecture and infrastructure intertwined. University of Virginia School of Architectures.

Doron, G. (2000). The dead zone and the architecture of transgression. City, 4(2), 247263.

Forman, R. T., Sperling, D., Bissonette, J. A., Clevenger, A. P., Cutshall, C. D., Dale, V. H., \& Franck, K. A. (2011). Occupying the edge and the underneath- "other" urban public spaces. In T. Hauck, R. Keller, \& V. Kleinekort (Eds.), In T. Hauck, R. Keller, \& V. Kleinekort (Eds.), Infrastructural urbanism - Addressing the inbetween (pp. 117-129). Berlin: DOM Publishers.

Franck, K. A. (2011). Occupying the edge and the underneath - "other" urban public spaces. In T. Hauck, R. Keller, \& V. Kleinekort (Eds.), Infrastructural urbanism - Addressing the in-between (pp. 117-129). Berlin: DOM Publishers.

Halprin, L. (1966). Freeways. New York: Reinhold Publishing Co.

Harnack, M., \& Kohler, M. (2011). As found. Use, meaning and re-appropriation of contentious urban spaces. In T. Hauck, R. Keller, \& V. Kleinekort (Eds.), Infrastructural urbanism - Addressing the in-between (pp. 131-144). Berlin: DOM Publishers.

Klia2.info. Malaysia Airport klia2. Retrieved from URL http://www.klia2.info/trips/highways/duke-duta-ulu-kelang-expressway

Kremer, P., \& Hamstead, Z. (2015). Transformation of urban vacant lots for the common good: an introduction to the special issue. Cities and the Environment (CATE), 8(2), 1.

Malterre Barthes, C. (2011). The highway's shadow. In T. Hauck, R. Keller, \& V. Kleinekort (Eds.), Infrastructural urbanism - Addressing the in-between (pp. $93-$ 108). Berlin: DOM Publishers.

Mossop, E. (2006). Landscapes of Infrastructure. In C. Waldheim (Ed.), The landscape urbanism reader (pp. 163-178). New York: Princeton Architectural Press. 
Mohamed Ikhwan Nasir Mohamed Anuar \& Raziah Ahmad

Exploring Possible Usage for Elevated Highway Interstitial Spaces: A case study of DUKE and AKLEH, Kuala Lumpur

Qamaruz-Zaman, N., Samadi, Z., \& Azhari, N. F. N. (2013). Under the flyovers of Kuala Lumpur: User centred activities in leftover spaces. Journal of Asian Behaviour Studies, 3(10), 89-103.

Prasetyo, F. A., \& Martin-Iverson, S. (2015). Playing under the fly over: A collaborative creative community in Bandung. Procedia-Social and Behavioral Sciences, 184 30-39.

Sanches, P. M. \& Pellegrino, P. R. M. (2016). Greening potential of derelict and vacant lands in urban areas. Urban Forestry \& Urban Greening, 19, 128-139.

Saouma, R. (2008). When a city embraces its paradoxes: Exploring the potential of public spaces under elevated highways: A case study in Bourj Hammoud, Beirut (Master's thesis). Wageningen University \& Research, Wageningen, the Netherlands.

Sola-Morales, I. (1995). Terrain vague. Cambridge: MA. MIT Press.

SWA Group (2011). Design briefing: Landscape infrastructure- a tool for making our cities better. (n.p.): SWA Group.

Trancik, R. (1986). Finding Lost Space: Theories of Urban Design. New York: Van Nostrand Reinhold.

Wall, E. (2011). Infrastructural form, interstitial spaces and informal acts. In T. Hauck, R. Keller, \& V. Kleinekort (Eds.), Infrastructural urbanism - Addressing the inbetween (pp. 145-157). Berlin: DOM Publishers. 